\title{
Rapid processing of ferrite ceramics with promising magneto-dielectric characteristics
}

\author{
Zhuohao Xiao*,†, , Chuanhu Wang ${ }^{\star}$, Lie Liu ${ }^{\S}$, Zhihong Yang \\ and Ling Bing Kong*,,$+ * *$ \\ ${ }^{*}$ School of Materials Science and Engineering \\ Jingdezhen Ceramic Institute \\ Jingdezhen 333001, P. R. China \\ ${ }^{\dagger}$ School of Materials Science and Engineering \\ Nanyang Technological University \\ 50 Nanyang Avenue, Singapore 639798 \\ *Department of Material and Chemical Engineering \\ Bengbu University, Bengbu 233030, Anhui, P. R. China \\ $\S_{\text {General Test Systems Inc. }}$ \\ Shenzhen, 518102, Guangdong, P. R. China \\ ${ }^{\top}$ College of Materials Science and Technology \\ Nanjing University of Aeronautics and Astronautics \\ Nanjing 211100, P. R. China \\ IIxiaozhuohao@126.com \\ **elbkong@ntu.edu.sg
}

Received 12 November 2017; Revised 30 November 2017; Accepted 1 December 2017; Published 18 December 2017

\begin{abstract}
Ferrite ceramics, $\mathrm{Ni}_{0.88} \mathrm{Zn}_{0.07} \mathrm{Co}_{0.05} \mathrm{Fe}_{1.98} \mathrm{O}_{4}$, with the addition of $4 \mathrm{wt} . \% \mathrm{Bi}_{2} \mathrm{O}_{3}$ as sintering aid, were fabricated by using a simple one-step processing without involving the step of calcination. X-ray diffraction (XRD) results indicated that single phase ferrite ceramics can be achieved after sintering at $1000^{\circ} \mathrm{C}$ for $2 \mathrm{~h}$. The samples demonstrated relative densities in the range of $97-99 \%$. Desired magneto-dielectric properties have been approached by adjusting the sintering temperature and sintering time duration. This technique is believed to be applicable to other ceramic materials.
\end{abstract}

Keywords: Ferrite; dielectric property; magnetic property; magneto-dielectric.

\section{Introduction}

Magneto-dielectric materials have almost equal values of permeability and permittivity over certain frequency bands. These materials may find many interesting applications, such as microwave attenuation ${ }^{1}$ and antenna miniaturization ${ }^{2,3}$ due to their near perfect matching with free space. In some cases, they must possess sufficiently low magnetic and dielectric loss tangents, for example, when used as antenna loading materials. Our recent studies indicate that ferrite ceramics can be used to develop magneto-dielectric materials. ${ }^{4-11}$ Two key strategies have been employed to achieve desirable magnetodielectric properties based on ferrite ceramics. Firstly, it is necessary to find out suitable sintering aid with an appropriate content to improve the densification behavior of ferrite so that fully dense products can be obtained at a relatively low temperature, therefore, the sintered ferrite ceramics have sufficiently low dielectric loss tangents. The following step is to adjust the magnetic properties to match permeability to permittivity.

Conventional ceramic technique is a multi-step processing method, involving mixing, milling, drying, crushing, calcination and sintering. Sometimes, double or triple calcination step has to be used to synthesize powders with desired compositions, which is therefore a process of very time consuming. A typical ceramic processing requires one week or even longer time to complete. It would be of great significance if a simple and cost-effective approach can be developed to fabricate ferrite ceramics. High-energy ball milling has been used to synthesize a wide range of oxide materials. ${ }^{12}$ Generally, a long time milling is required to synthesize materials with a targeted composition via highenergy ball milling. Kong et al. ${ }^{13}$ found that lead zirconate titanate $\left(\mathrm{PbZr}_{0.52} \mathrm{Ti}_{0.48} \mathrm{O}_{3}\right.$ or PZT) can be readily derived from the oxide mixture milled for a relatively short time duration where the PZT phase is not yet formed, so that reaction

\section{$\|, * *$ Corresponding authors.}

This is an Open Access article published by World Scientific Publishing Company. It is distributed under the terms of the Creative Commons Attribution 4.0 (CC-BY) License. Further distribution of this work is permitted, provided the original work is properly cited. 
sintering was involved during the sintering process. In this paper, we will demonstrate that this technique is also applicable to the fabrication of ferrite ceramics. According to our previous studies, ${ }^{11}$ the ferrite selected has a composition of $\mathrm{Ni}_{0.88} \mathrm{Zn}_{0.07} \mathrm{Co}_{0.05} \mathrm{Fe}_{1.98} \mathrm{O}_{4}$, with the addition of 4 wt. $\% \mathrm{Bi}_{2} \mathrm{O}_{3}$ as sintering aid. Fully dense ferrite ceramics with desired magneto-dielectric properties can be prepared through a onestep process.

\section{Experimental}

Spinel ferrite ceramics, with a composition of $\mathrm{Ni}_{0.88} \mathrm{Zn}_{0.07}$ $\mathrm{Co}_{0.05} \mathrm{Fe}_{1.98} \mathrm{O}_{4}$, with the addition of 4 wt. $\% \mathrm{Bi}_{2} \mathrm{O}_{3}$, were simply fabricated via a one-step processing. Commercially available $\mathrm{NiO}$ (99\% purity, Aldrich Chemical Company Inc., USA), $\mathrm{Fe}_{2} \mathrm{O}_{3}$ (99\% purity, Aldrich Chemical Company Inc., USA), $\mathrm{ZnO}$ (99+\% purity, Aldrich Chemical Company Inc., USA), $\mathrm{Co}_{3} \mathrm{O}_{4}(99+\%$ purity, Aldrich Chemical Company Inc., USA) and $\mathrm{Bi}_{2} \mathrm{O}_{3}(99 \%$ purity, Aldrich Chemical Company Inc., USA) powders, were used as starting materials, among which $\mathrm{NiO}$ and $\mathrm{Fe}_{2} \mathrm{O}_{3}$ powders were preannealed at $1000^{\circ} \mathrm{C}$ for $2 \mathrm{~h}$ to ensure the valances of $\mathrm{Ni}$ and $\mathrm{Fe}$ to be +2 and +3 , respectively. The mixture of the starting materials was milled by a high-energy ball mill for $1 \mathrm{~h}$, using a Retsch PM400 type planetary ball milling machine. A $250 \mathrm{ml}$ tungsten carbide vial and 100 tungsten carbide balls with diameter of $10 \mathrm{~mm}$ were used as a milling medium. The milling speed was set at $200 \mathrm{rpm}$. The milled powder was collected, compacted and then sintered at $1000^{\circ} \mathrm{C}, 1050^{\circ} \mathrm{C}$ and $1100^{\circ} \mathrm{C}$, for $2,4,8$ and $12 \mathrm{~h}$ at each temperature.

Two types of samples, namely disk (diameter of $\sim 10 \mathrm{~mm}$ and thickness of $\sim 1.5 \mathrm{~mm}$ ) and toroidal (outer diameter of $\sim 20 \mathrm{~mm}$, inner diameter of $\sim 10 \mathrm{~mm}$ and thickness of $\sim 2.5 \mathrm{~mm}$ ), were prepared. Disk samples were used in the measurement of permittivity, while toroidal samples were used in the measurement of permeability. Phase compositions of the mixed, milled and sintered samples were analyzed using a Philips PW 1729 type X-ray diffractometer (XRD) with $\mathrm{Cu} \mathrm{K}_{\alpha}$ radiation. Grain size and grain morphology of the sintered samples were examined using a JEOL JSM-6340F type field emission scanning electronic microscope (FESEM). Densities of the ferrite ceramics were derived from the masses and dimensions of the samples. Complex relative permeability and permittivity of the ferrite ceramics were measured using the Agilent E4991A RF impedance/materials analyzer over $1 \mathrm{MHz}-1 \mathrm{GHz}$.

\section{Results and Discussion}

XRD result of the mixed powder after milling for $1 \mathrm{~h}$ indicates that no reaction occurred during the milling process, but the diffraction peaks of the oxide precursors were significantly reduced and broadened. It means that the one-hour milling has greatly refined the starting powders, which is the

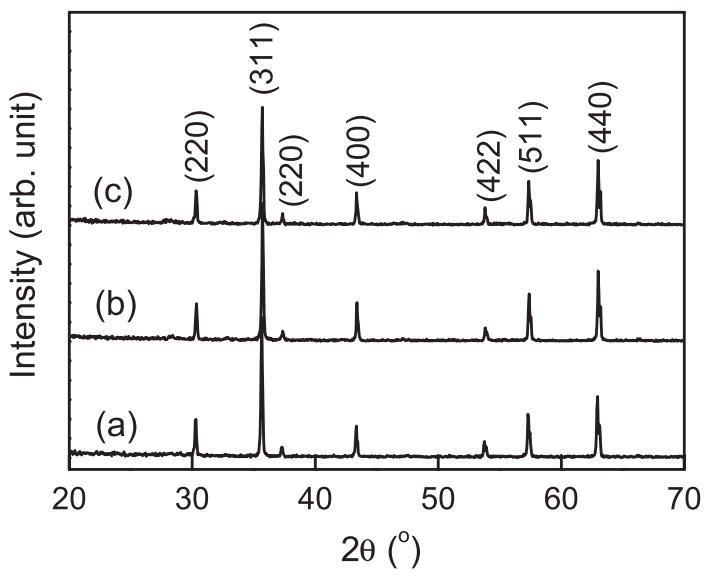

Fig. 1. XRD patterns of the samples sintered for $2 \mathrm{~h}$ at different temperatures: (a) $1000^{\circ} \mathrm{C}$, (b) $1050^{\circ} \mathrm{C}$ and (c) $1100^{\circ} \mathrm{C}$.

main reason why the mixture can be used to obtain the ferrite ceramics via one-step sintering. Figure 1 shows the XRD patterns of the three samples sintered at $1000^{\circ} \mathrm{C}, 1050^{\circ} \mathrm{C}$ and $1100^{\circ} \mathrm{C}$ for $2 \mathrm{~h}$. All the main diffraction peaks can be assigned to spinel structure of ferrite. No peaks from other phases can be obviously observed from the XRD patterns, which means that the reaction of the starting components to the ferrite spinel has been completed after sintering for $2 \mathrm{~h}$. XRD patterns of the samples sintered for longer time durations are similar to those shown in Fig. 1, which thus are not included in this paper.

Freshly fractured surface SEM images of the ferrite ceramics are shown in Figs. 2 and 3. As seen in Fig. 2, the sample sintered at $1000^{\circ} \mathrm{C}$ for $2 \mathrm{~h}$ has an inhomogeneous microstructure, where a small number of large grains are randomly distributed in matrix of small ones. After sintering for $4 \mathrm{~h}$, the microstructure of the sample is similar to that of the sample sintered for $2 \mathrm{~h}$. However, the sizes of both the large and small grains are increased. At the same time, there are more large grains and less small grains. Such a variation continues with sintering time. Figure 3(a) indicates that the sample sintered at $1050^{\circ} \mathrm{C}$ for $2 \mathrm{~h}$ exhibits a microstructure which is between the two samples sintered at $1000^{\circ} \mathrm{C}$ for $4 \mathrm{~h}$ and $8 \mathrm{~h}$ (Figs. 2(b) and 2(c)). Sintering at $1050^{\circ} \mathrm{C}$ for $8 \mathrm{~h}$ resulted in sample with an almost fully dense microstructure (Fig. 3(c)). The samples sintered at $1100^{\circ} \mathrm{C}$ possess microstructures similar to that of Fig. 3(d), with grain size increasing gradually with time duration, which are not included in this paper. The microstructure development of the ferrite ceramics is in a good agreement with the density measurement. The measured densities of the samples are between $97 \%$ and $99 \%$ of their theoretical density.

Reaction sintering is a promising technique to fabricate ceramic materials, in which the designed compound has not been synthesized and the reactions between constituent phases take place during sintering process at high temperatures. It is advantageous over the above mentioned methods because of its simple processing procedure and enhanced 


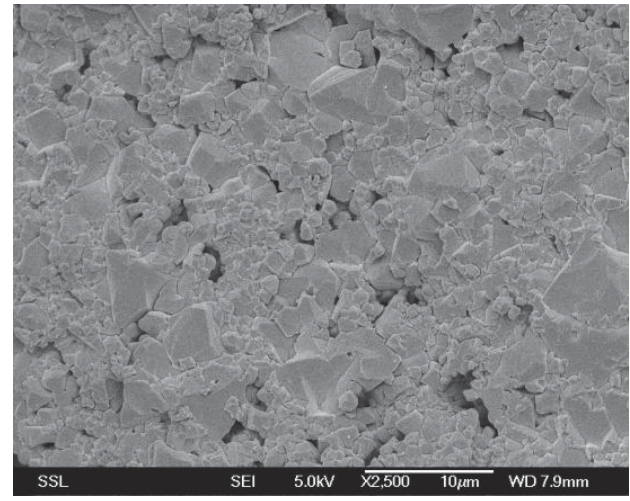

(a)

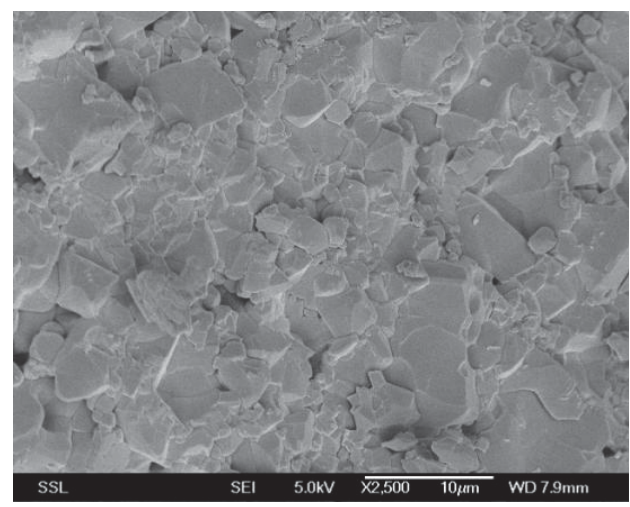

(c)

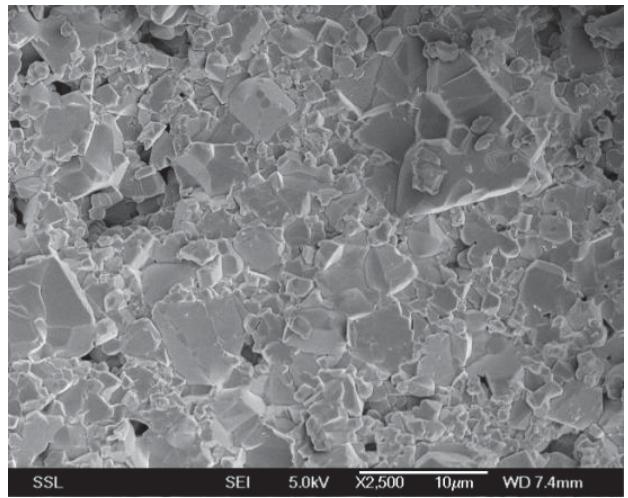

(b)

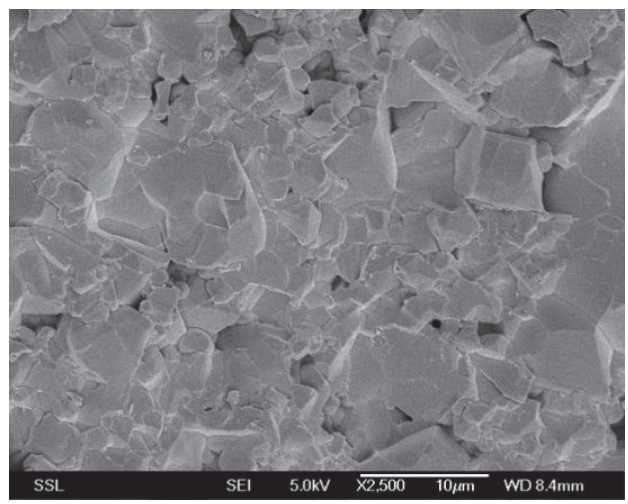

(d)

Fig. 2. SEM images of the samples sintered at $1000^{\circ} \mathrm{C}$ for different time durations: (a) $2 \mathrm{~h}$, (b) $4 \mathrm{~h}$, (c) $8 \mathrm{~h}$ and (d) $12 \mathrm{~h}$.

densification progress. As mentioned above, PZT ceramics have been successfully prepared directly from the oxide mixture mill for a short time duration. An enhanced densification was found at a low temperature which is believed to be the result of a reactive sintering during the perovskite formation of PZT. ${ }^{13}$ The formation of the ferrite ceramics in the present study should be similar.

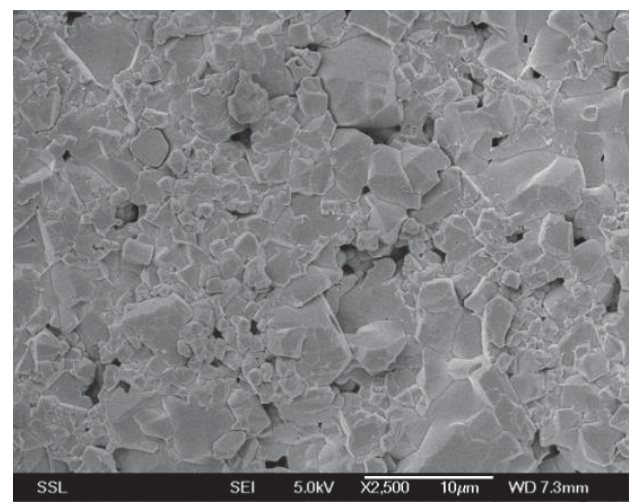

(a)
Figure 4 shows a representative complex relative permittivity curve of the ferrite ceramics. The sample was sintered at $1100^{\circ} \mathrm{C}$ for $4 \mathrm{~h}$. The relatively high noise at low frequencies (below $3 \mathrm{MHz}$ ) and the rise in both real and imaginary permittivity at high frequencies (above $300 \mathrm{MHz}$ ) are intrinsic properties of the materials, which will not be discussed in this paper. It is found that both real and imaginary parts of

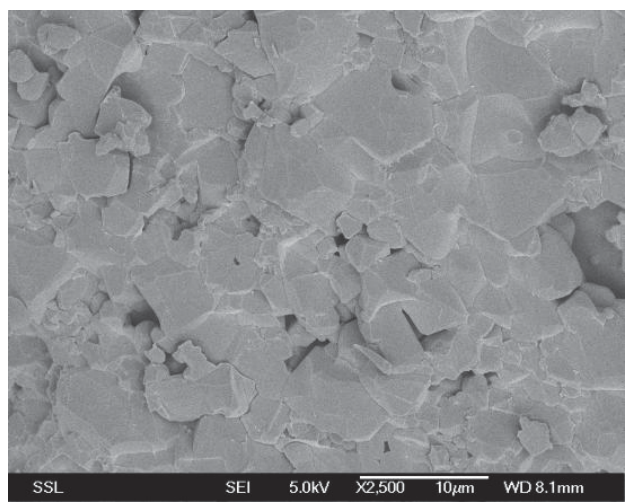

(b)

Fig. 3. SEM images of the samples sintered at $1050^{\circ} \mathrm{C}$ for different time durations: (a) $2 \mathrm{~h}$, (b) $4 \mathrm{~h}$, (c) $8 \mathrm{~h}$ and (d) $12 \mathrm{~h}$. 


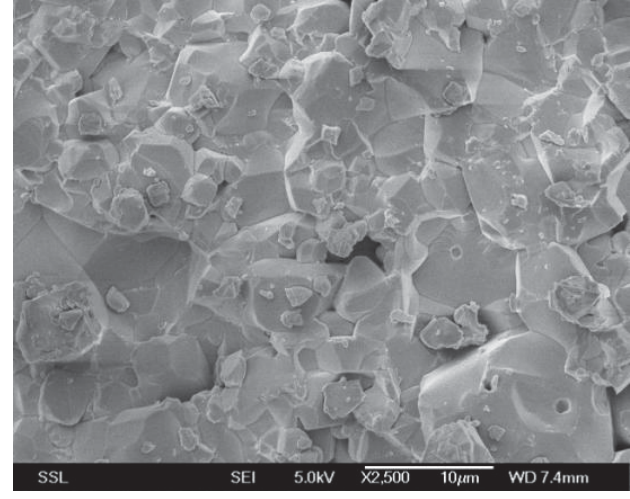

(c)

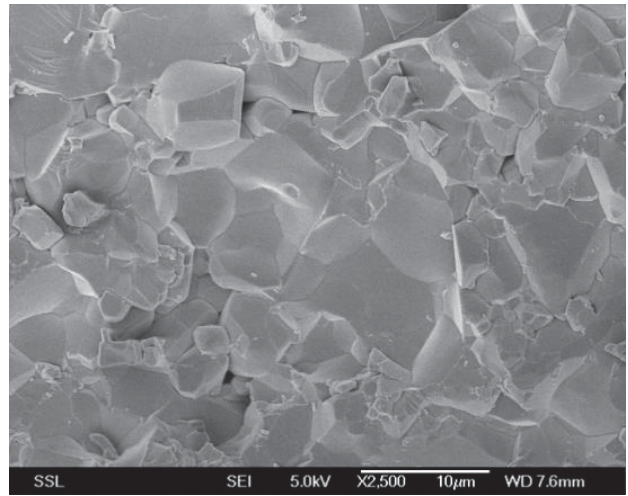

(d)

Fig. 3. (Continued)

permittivity are almost constant versus frequency (below $300 \mathrm{MHz}$ ) and the corresponding dielectric loss tangents are well less than $10^{-2}$, which is sufficiently low to meet the requirement for engineering applications, such as antenna design. There is no significant variation in complex permittivity among the samples sintered at different temperatures and kept for different time durations.

Dielectric loss tangent $\left(\tan \delta_{\varepsilon}=\varepsilon^{\prime \prime} / \varepsilon^{\prime}\right)$ of polycrystalline ferrite ceramics is due to the lag in polarization versus the alternating electric field, which is determined by several factors, such as the presence of impurities and the imperfection in the ferrite structure. ${ }^{9}$ However, the most significant contribution to dielectric loss tangent comes from the conduction loss due to poor densification and electron hopping between $\mathrm{Fe}^{2+}$ and $\mathrm{Fe}^{3+}$ ions. The loss tangents caused by conduction loss are observable, especially at low frequencies. Poor densification caused dielectric loss is mainly attributed to the presence of large volumetric fraction of pores (especially open ones) that are easily contaminated by absorbing impurities or water vapors from air. All these factors are responsible for increase of conductivity of ferrite ceramics. The presence of $\mathrm{Fe}^{2+}$ ions is mainly related to the high sintering

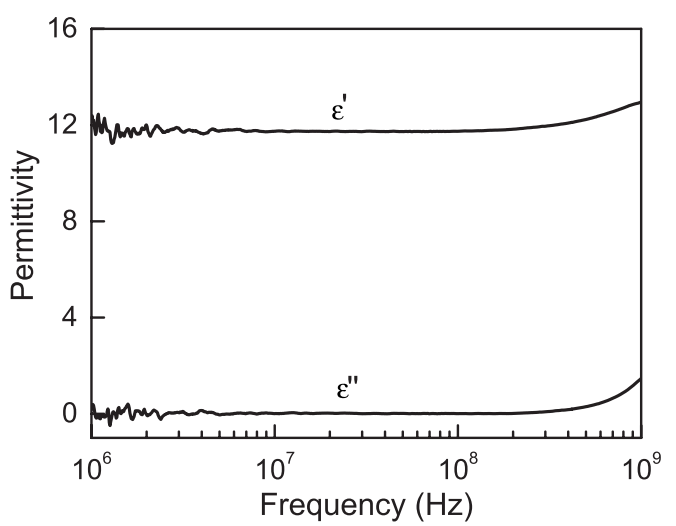

Fig. 4. Representative complex permittivity curve of the ferrite ceramics (sintered at $1100^{\circ} \mathrm{C}$ for $4 \mathrm{~h}$ ). temperature. In the present study, 4 wt. $\% \mathrm{Bi}_{2} \mathrm{O}_{3}$ was used as sintering aid to ensure a full densification of the ferrite ceramics at low temperature, so that both conduction losses caused by pores and $\mathrm{Fe}^{2+}$ ions have been avoided. These observations are in a good agreement with the results of microstructure and densification of the ferrite ceramics as discussed above.

Figure 5 shows relative complex permeability curves of representative samples of the ferrite ceramics. The complex permeability spectra of the ceramics exhibit a common feature. The real permeability $\mu^{\prime}$ remains almost constant up to a certain frequency, beyond which $\mu^{\prime}$ begins to decrease. The imaginary permeability $\mu^{\prime \prime}$ remains very low for frequencies below several tens $\mathrm{MHz}$, and increases above a certain frequency. The peak shifts to lower frequency as the real permeability increases. To characterize the magnetic properties of ferrite materials, a static permeability $\mu_{0}$ is usually used, which is defined as the real permeability far below the resonance frequency $f_{r}$, corresponding to the maximum imaginary permeability in the $\mu^{\prime \prime}-f$ curve. Here, we use the real permeability at $1 \mathrm{MHz}$ as the static permeability. Magnetic loss tangent is defined as $\tan \delta_{\mu}=\mu^{\prime \prime} / \mu^{\prime}$. It has been found that the magnetic loss tangent of the ferrite ceramics in the

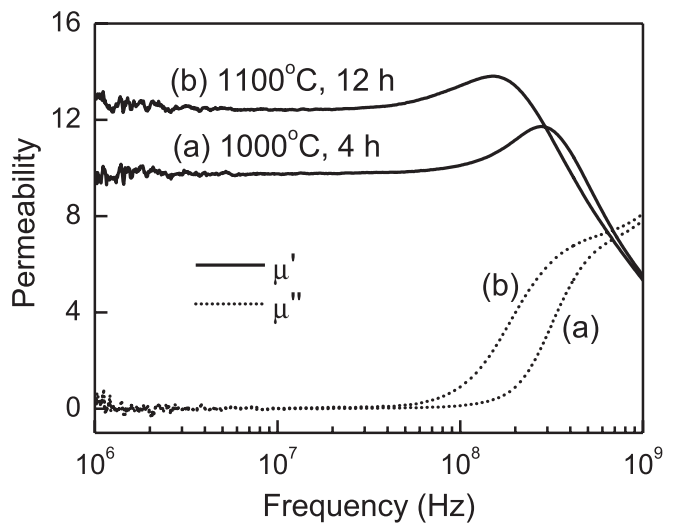

Fig. 5. Representative complex permeability curve of the ferrite ceramics. 


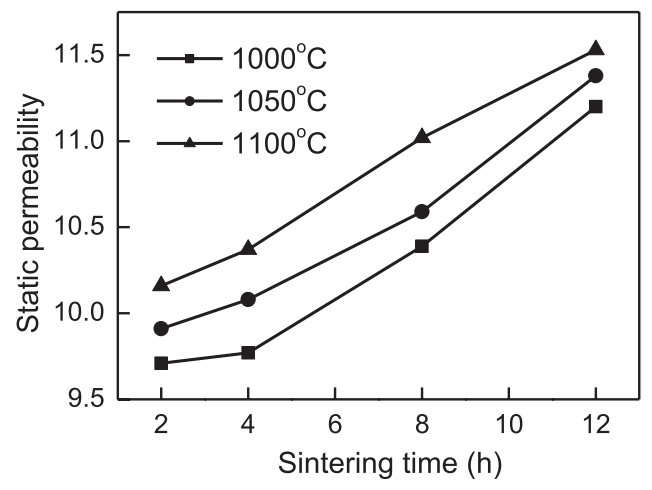

Fig. 6. Static permeability of the ferrite ceramics as a function of sintering time at different temperatures.

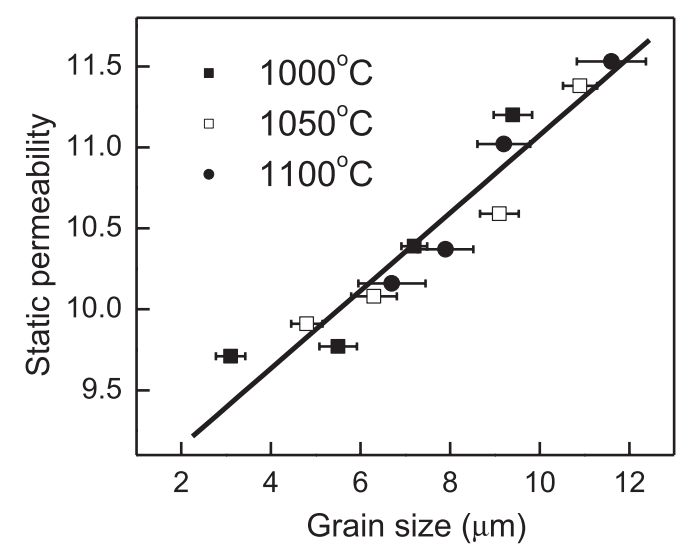

Fig. 7. Static permeability versus grain size of the ferrite ceramics. present study is sufficiently low $\left(<10^{-2}\right)$ as long as the frequencies considered are far below the resonance frequencies. At the same time, the real part of permeability at low loss frequency region is almost constant versus frequency. There is no significant variation in magnetic loss tangent of the samples with sintering temperature at frequencies far below the resonance frequency.

Generally, the product of resonance frequency $\left(f_{r}\right)$ and static permeability $\left(\mu_{0}-1\right)$ for spinel ferrites can be expressed as a constant by the Snoek-like law $\left(\mu_{0}-1\right) f_{r}=C$. For natural resonance, $C=(2 / 3) \gamma M_{s}$ (where $\gamma$ is the gyromagnetic ratio and $M_{s}$ is the saturation magnetization). ${ }^{14}$ For wall resonance, $C=C_{1} M_{s}^{2}$ (where $C_{1}$ is a constant related to the domain size and the thickness of domain wall). ${ }^{15}$ Therefore, a high static permeability leads to low resonance frequency, for a given composition, as demonstrated in Fig. 5.

Static permeability values of the samples as a function of sintering time are shown in Fig. 6. At a given sintering temperature, the static permeability increases monotonically with sintering time duration. For a given sintering time, the static permeability increases with sintering temperature.

A model proposed by Globus ${ }^{16}$ can be used to describe the relationship between static permeability and microstructure of the ferrite ceramics. When accounting for the permeability of ferrites, two contributions, spin-rotation and domain wall motion, must be considered. According to Globus's model, ${ }^{16}$ the portion of permeability contributed by domain-wall-motion is linearly dependent on grain size, while the permeability contributed by spin-rotation is independent of grain size. Figure 7 shows static permeability
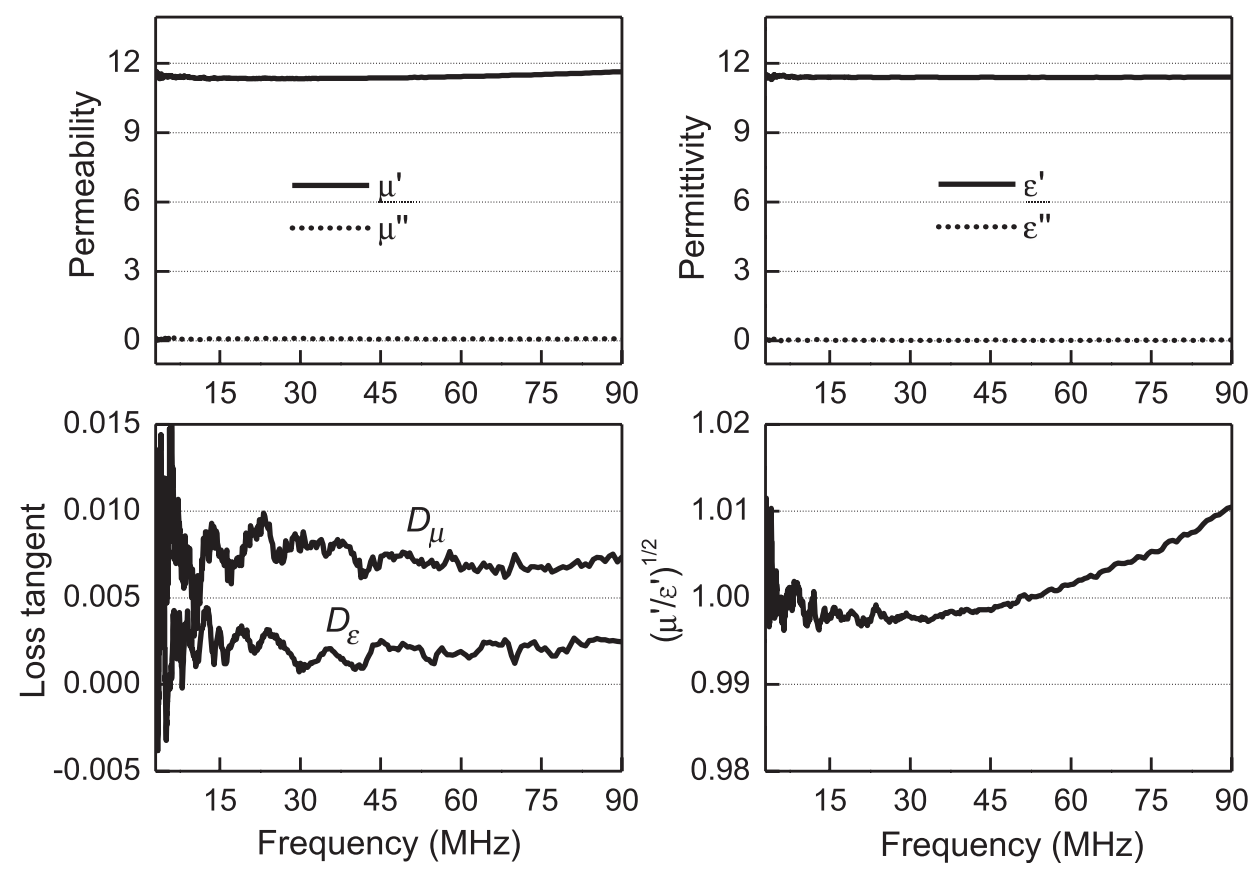

Fig. 8. Typical magneto-dielectric property of the ferrite ceramics (sintered at $1100^{\circ} \mathrm{C}$ for $4 \mathrm{~h}$ ). 
of the samples as a function of grain size estimated from the corresponding SEM images. Linear fitting to the data results in an equation, $\mu_{0}=8.67+0.24 D$. The intercept of 8.67 could be attributed to the part contributed only by the spin rotation. Similar results have been observed for other ferrite ceramics in our previous studies. $^{6,9,11}$

Conventional antennas for the frequency band of $3-30 \mathrm{MHz}$ (HF) and $30-300 \mathrm{MHz}$ (VHF) are physically large, and therefore not suitable for portable applications. A pertinent challenge is to reduce the physical dimensions without affecting its electrical performances. From the laws of physics, it is potentially possible to use material loading to scale down the antenna's physical dimension by a factor of $n$ (refractive index of material), with its electrical dimension unchanged. A class of materials that serves this purpose is the magneto-dielectric materials with high refractive index ( $n=\sqrt{\mu^{\prime} \varepsilon^{\prime}}$, where $\mu^{\prime}$ is relative permeability and $\varepsilon^{\prime}$ is relative permittivity), ${ }^{2,3}$ and almost matching $\mu^{\prime}$ and $\varepsilon^{\prime}(Z=$ $\sqrt{\mu_{0}^{\prime} \mu^{\prime} / \varepsilon_{0}^{\prime} \varepsilon^{\prime}}=\eta_{0} \sqrt{\mu^{\prime} / \varepsilon^{\prime}}=\eta_{0}$, where $\eta_{0}$ is impedance of free space). The latter condition is particularly important for matching the antenna impedance to free space environment. Moreover, the materials must have sufficiently low magnetic and dielectric loss tangent $\left(\leq 10^{-2}\right)$ to minimize losses in the antennas. Figure 8 shows a representative magneto-dielectric property of the ferrite ceramics (sintered at $1100^{\circ} \mathrm{C}$ for $4 \mathrm{~h}$ ). Over $3-90 \mathrm{MHz}$, the real permeability and permittivity are almost equal, which leads to an impedance very close to that of free space by a deviation of less than $1 \%$. The magnetic loss is less than $10^{-2}$ while the dielectric loss is lower than $5 \times 10^{-3}$, both of which are well below the requirement of practical applications. Therefore, the ferrite ceramics prepared by this simple process are promising candidates in the applications of HF and VHF antenna miniaturization.

\section{Conclusions}

In conclusion, magneto-dielectric ferrite ceramics have been prepared via a one-step processing and can be achieved in two day time, which is much faster than required by the conventional ceramic technique. By making use of $4 \mathrm{wt} . \% \mathrm{Bi}_{2} \mathrm{O}_{3}$ as sintering aid, almost fully dense $\mathrm{Ni}_{0.88} \mathrm{Zn}_{0.07} \mathrm{Co}_{0.05} \mathrm{Fe}_{1.98} \mathrm{O}_{4}$ ceramics (97-99\% of theoretical density) can be obtained after sintering at relatively low temperature, which is critical to the ensure sufficiently low dielectric loss tangents of the materials. The magnetic properties of the samples, versus sintering temperature and time duration, are well explainable according to Globus's model. The materials have promising magneto-dielectric properties for possible antenna miniaturization. This fast and costeffective method should be applicable to other materials.

\section{Acknowledgments}

This work was supported by the Natural Science Fund of China (51762023), the JiangXi Association for Science and
Technology, the Jiangxi Provincial Department of Education, and the Training Program of Outstanding Young Scientists in Jiangxi Province (20171BCB23070).

\section{References}

${ }^{1}$ W. Yu, R. Mettra and D. H. Werner, FDTD modeling of an artificially synthesized absorbing medium, IEEE Microwave Guided Wave Lett. 9, 496 (1999).

${ }^{2}$ H. Mosallaei and K. Sarabandi, Magneto-dielectrics in electromagnetics: Concept and applications, IEEE Trans. Antennas Propag. 52(6), 1558 (2004).

${ }^{3}$ K. Buell, H. Mosallaei and K. Sarabandi, A substrate for small patch antennas providing tunable miniaturization factors, IEEE Trans. Microwave Theory Tech. 54(1), 135 (2006).

${ }^{4}$ L. B. Kong, Z. W. Li, G. Q. Lin and Y. B. Gan, Magneto-dielectric properties of $\mathrm{Mg}-\mathrm{Cu}-\mathrm{Co}$ ferrite ceramics: I. Densification behavior and microstructure development, J. Am. Ceram. Soc. 90(10), 3106 (2007).

${ }^{5}$ L. B. Kong, Z. W. Li, G. Q. Lin and Y. B. Gan, Magneto-dielectric properties of $\mathrm{Mg}-\mathrm{Cu}-\mathrm{Co}$ ferrite ceramics: II. Electrical, dielectric and magnetic properties, J. Am. Ceram. Soc. 90(7), 2104 (2007).

${ }^{6}$ L. B. Kong, Z. W. Li, G. Q. Lin and Y. B. Gan, $\mathrm{Mg}_{1-x} \mathrm{Co}_{x} \mathrm{Fe}_{1.98} \mathrm{O}_{4}$ ceramics with promising magneto-dielectric properties as potential candidate for antenna miniaturizations, IEEE Trans. Mag. 44 (5), 559 (2008).

${ }^{7}$ M. L. S. Teo, L. B. Kong, Z. W. Li, G. Q. Lin and Y. B. Gan, Development of magneto-dielectric materials based on Li-ferrite ceramics: I. Densification behavior and microstructure development, J. Alloys Compd. 459(1-2), 557 (2008).

${ }^{8}$ M. L. S. Teo, L. B. Kong, Z. W. Li, G. Q. Lin and Y. B. Gan, Development of magneto-dielectric materials based on Li-ferrite ceramics: II. DC resistivity and complex relative permittivity, $J$. Alloys Compd. 459(1-2), 567 (2008).

${ }^{9}$ L. B. Kong, M. L. S. Teo, Z. W. Li, G. Q. Lin and Y. B. Gan, Development of magneto-dielectric materials based on Li-ferrite ceramics: III. Complex relative permeability and magneto-dielectric properties, J. Alloys Compd. 459(1-2), 576 (2008).

${ }^{10}$ K. C. Chan, X. T. Liew, L. B. Kong, Z. W. Li and G. Q. Lin, $\mathrm{Ni}_{1-x} \mathrm{Co}_{x} \mathrm{Fe}_{1.98} \mathrm{O}_{4}$ ferrite ceramics with promising magnetodielectric properties, J. Am. Ceram. Soc. 91(12), 3937 (2008).

${ }^{11}$ X. T. Liew, K. C. Chan and L. B. Kong, Magneto-dielectric Niferrite ceramics with $\mathrm{Bi}_{2} \mathrm{O}_{3}$ additive for potential antenna miniaturizations, J. Mater. Res. 24(2), 324 (2009).

${ }^{12}$ L. B. Kong, T. S. Zhang, J. Ma and Y. C. F. Boey, Progress in synthesis of ferroelectric ceramic materials via high-energy mechanochemical techniques, Prog. Mater. Sci. 53(2), 207 (2008).

${ }^{13}$ L. B. Kong, J. Ma, W. Zhu and O. K. Tan, Reaction sintering of partially reacted system for PZT ceramics via a high-energy ball milling, Scr. Mater. 44, 345 (2001).

${ }^{14}$ J. L. Snoek, Dispersion and absorption in magnetic ferrites at frequencies above One Mc/s, Physica 14(4), 207 (1948).

${ }^{15}$ J. Verwell, Magnetic Properties of Materials, ed. J. Smith (McGraw-Hill, US, 1971), p. 64.

${ }^{16}$ A. Globus, Some physical consideration about the domain wall size theory of magnetisation mechanisms, J. Phys. Colloq. 1(4), C1 (1978). 